\title{
PROSPECTIVE BIOREPOSITORY PARTICIPANTS' PERSPECTIVES ON ACCESS TO RESEARCH RESULTS
}

\author{
Laura M. Beskow and \\ Duke University \\ Sondra J. Smolek \\ University of North Carolina
}

\begin{abstract}
Disclosure of individual research results to research participants has been the subject of professional guidelines as well as scholarly commentary, yet controversy remains. To gather data on participant perspectives, we interviewed 40 individuals from the Durham, North Carolina area about a biorepository consent form and conducted an in-depth analysis of responses to a series of questions concerning access to research results. Cross-cutting themes emerged about (1) the nature of research; (2) the nature of research results; (3) expectations concerning access to research results; and (4) practical issues in providing access to research results. Our findings highlight the importance for sound policy development of soliciting stakeholder input, and exploring the complexities behind their evaluations.
\end{abstract}

\section{Keywords}

biorepository; biological specimen banks; informed consent; research subjects; confidentiality; disclosure of research results; access to research results

Considerable controversy exists over the issue of disclosing individual research results to research participants. This topic has been the subject of guidelines from federal and international entities (Bookman et al., 2006; Knoppers et al., 2006; National Bioethics Advisory Commission, 1999) as well as ample scholarly commentary, and yet the debate continues range widely between the view that individual results should routinely be offered (Fernandez, 2008; Sharp \& Foster, 2006; Shalowitz \& Miller, 2005; Fernandez, Kodish, \& Weijer, 2003) and the view that such results should seldom, if ever, be disclosed (Miller et al., 2008; Meltzer, 2006; Parker, 2006; Clayton \& Ross, 2006). Many the same ethical principles - respect for persons, beneficence, and reciprocity—are applied in arguments both for and against disclosure of results (Haga \& Beskow, 2008).

Data on the opinions and preferences of stakeholders are essential for informing policy development on this issue. Surveys employing basic questions about research results appear to document participants' desire to receive such information (Kaufman et al., 2008; Wendler $\&$ Emanuel, 2002). However, the preponderance of positive responses may not accurately reflect what participants' nuanced preferences would be if they were given a more complete portrayal of the limited validity and utility of most research findings (Ormond et al., 2009). In 
addition, many studies (as well as broader discussions on this topic) have focused on the disclosure of results generated in the context of clinical trials (Partridge et al., 2009; DixonWoods et al., 2006; Partridge et al., 2003) and other well-defined studies (Schulz et al., 2003; Richards et al., 2003). Less attention has been given to the context of a biorepository, where participants may be enrolled based simply on their membership in a particular population (e.g., geographically defined) and not because they have a particular condition of interest. Specimens and data are stored for future, unspecified use in a variety of studies that typically take place without the subject's direct knowledge or consent. These studies are most often conducted without any interaction with the researcher, who may be unknown to the participant. These differences between biorepository research and other kinds of studies may result in participants perceiving a different stake in the research, and thus having different expectations concerning access to research results.

The purpose of our study was to explore the opinions of prospective biorepository participants about access to research results, gathered through cognitive interviews conducted about a consent form developed for a proposed biorepository at Duke University. During these interviews, we asked participants about many topics addressed in the form, including the purpose of the biorepository, indefinite storage of specimens and data, ongoing medical record access, contact to update personal information, contact about additional research, types of researchers who might access the biorepository, risks and benefits, development of commercial products, access to research results, and the ability to withdraw. The major findings on each of these topics have been published elsewhere (Beskow \& Dean, 2008).

Because of the wide range of topics covered in that first report, opinions gathered in response to questions about access to research results were summarized at a relatively high level. Here we provide a more in-depth analysis of cross-cutting themes that emerged in response to those questions. These themes represent important input from a key stakeholder group that may be useful to consider when designing biorepository policies, procedures, and consent documents, as well as future research to further elucidate this complex issue.

\section{Methods \\ Original Data Collection}

We conducted cognitive interviews to gather input on a consent form created for a proposed Duke biorepository based on federal regulations and best practice guidelines. We designed an interview protocol (available upon request) that focused on participants' (1) understanding of information conveyed in the form, and (2) opinions about that information. Institutional Review Boards at Duke University and the Research Triangle Institute (RTI) determined that the research was exempt from review (45CFR46.101[b][2]).

We recruited 40 participants from the Durham, North Carolina area, using newspaper advertisements, Internet postings, and flyers placed in Duke clinics and several community locations. We screened respondents by telephone to over-sample minorities and people with lower educational attainment, to achieve diversity by age and sex, and to avoid habitual research participants.

Interviews took place from May to October 2007 at RTI's Laboratory for Survey Methods and Measurement. We used an iterative approach, revising the form and the interview questions based on feedback gathered in each of four rounds of interviews. Participants were first asked to read the entire consent form, and were then interviewed in person by one of two professional interviewers. All interviews were digitally recorded and lasted an average of 30 minutes. Participants gave oral consent and received $\$ 40$ for participating. 
The consent form text that addressed access to research results is shown in Figure 1. The section of the interview protocol devoted to this text is shown in Figure 2. Additional details concerning original data collection procedures are available elsewhere (Beskow \& Dean, 2008).

\section{Methods for this Analysis}

For all interviews, the sections on access to research results were transcribed verbatim, and the transcripts reviewed to verify accuracy.

Coding and analysis of the data using NVivo (v.8) proceeded in several stages to ensure the validity and consistency of the codes and their applications. One author (SJS), who was not involved in the original analysis, independently performed initial open coding to identify common themes that emerged within a sample $(n=25)$ of the interviews. This allowed concepts to emerge from respondents' statements that reflected the range of perspectives embedded in the data, rather than imposing an existing set of concepts onto the data. Both authors discussed the codes to refine their specific definitions and characteristics, and then separately applied the coding scheme to the initial sample. At that point, the authors compared their coding, refined and organized concepts hierarchically under major themes where appropriate, and discussed any discrepancies before applying the scheme to the entire sample. The authors ultimately achieved a high degree of agreement in the application of the coding scheme, and reconciled discrepancies prior to the analyses. Tools in NVivo were then used to identify the most commonly used codes, as well as relationships among codes.

\section{Results}

\section{Interviewee Characteristics}

As previously reported (Beskow \& Dean, 2008), the study population was diverse. Approximately $40 \%$ of the interviewees were male, nearly $25 \%$ were age 55 or older, and $75 \%$ self-reported their race in a category other than white. Approximately $60 \%$ reported their education level as less than a bachelor's degree and only $15 \%$ said they had participated in any kind of research interview or study in the past year.

\section{Summary of Previously Reported Results}

Responses to a subset of the interview questions concerning access to research results have already been reported (Beskow \& Dean, 2008). In brief, when asked "What do you think about the statement in the consent form that 'you should not expect to get individual results from research done with your blood'?" the comments of approximately two-thirds of interviewees suggested they were comfortable with it. However, when asked, "If researchers discovered something serious about your health, do you think they should let you know about it?" slightly more than three-fourths of interviewees said yes. In response to the question, "How important would it be to you to be able to get general news about studies being done through the biorepository?" just over two-thirds of the interviewees said it would be important.

In addition, most (85\%) interviewees said that, if asked, they would take part in the biorepository, i.e., allow their blood and information to be stored indefinitely for use in future research. Among those who said yes, $86 \%$ said they would agree to periodic contact to update their personal information, 67\% said they would allow ongoing access to their medical records, and $94 \%$ said they would be willing to be contacted in the future about additional research.

Two overarching conclusions were drawn from these findings (Beskow \& Dean, 2008). First, most interviewees were comfortable not receiving individual research results as a matter of routine, but many thought they should be informed of findings with serious implications for their health. Second, biorepositories should devise ways to communicate clearly about the 
research being conducted and what is being learned, as a way of honoring participants' altruism and to reassure them that their specimens and data are being put to good use.

\section{Cross-Cutting Themes}

Upon further analysis, several salient themes emerged across all of the interview questions concerning access to research results. These included general attitudes toward the nature of research and the nature of research results, as well as expectations and practical considerations concerning access to research results.

CROSS-CUTTING THEME 1: THE NATURE OF RESEARCH—Interviewees commonly made statements about the nature of research-sometimes in relation to medical care, and sometimes by comparing researchers' and doctors' obligations or knowledge-when discussing their expectations concerning access to research results.

Approximately $30 \%$ of interviewees made comments about research relative to medical care (Table 1a). Most often, these comments were made spontaneously in the context of the question, "What do you think about the statement that "you should not expect to get individual results from research done with your blood'?" Almost all described differences between the two, noting for example that research was "not like a regular doctor visit" where one would expect diagnosis, treatment, and followup. Some specifically noted a difference between a biological sample that could "sit on a shelf with a million others" and individual medical care, although a few felt that a personal connection remained between a biospecimen and the individual from whom it came. At least one respondent indicated a view that participation in the biorepository represented relinquishing ownership of the sample, stating that she was not bothered by lack of access to individual results because "once I give it, it's theirs."

Nearly half of interviewees referred to the obligations of physicians versus researchers (Table 1b). The first 10 interviewees were asked directly, "When you think about biorepository researchers and your own doctor, how would you compare their responsibilities when it comes to communicating something important about your health?" Almost all described a difference in their responsibilities, portraying doctors as having an obligation to deliver results and treat their patients whereas researchers do not. Later interviewees expressed a similar contrast even when not asked the direct question, but rather, for example, in the general context of saying why they would not expect to get individual results:

INTERVIEWER: What do you think about the statement that "you should not expect to get individual results from research done with your blood"?

SUBJECT: I wouldn't expect results from researchers, as opposed to my medical doctor.

INTERVIEWER: Does that mean you think what the researchers do with the biorepository blood is just ... that's not something you're ever going to get results from? You would only ever expect to get results from what your regular doctor does?

SUBJECT: Exactly. (\#13: Black female, age 55+, some college but no degree)

Some recognized a difference between researchers' and physicians' obligations, but still felt they should get individual results - particularly results with significant implications for their health so that they could seek treatment. A few interviewees saw no difference between researchers' and physicians' obligations with regard to communicating health information, grouping them together as "medical professionals." 
Finally, approximately $40 \%$ of interviewees commented on physician versus researcher knowledge (Table 1c). Some felt that their physician would already have discovered any problems with their health, expressing doubt that research results would represent information their physician did not already know. Others, however, thought researchers might have more or newer knowledge than their physician would have, and gave this as a reason they should get individual results. Even perceiving researchers as having more knowledge, at least one interviewee expected researchers to educate all doctors about new discoveries, rather than provide individual results:

SUBJECT: I think the researchers probably will have a little more information than the doctors since they're the ones conducting the tests and actually have been involved with the process. So to me they would be the ones educating the doctors on what was discovered.

INTERVIEWER: Do you think they would be educating the doctors on your specific results?

SUBJECT: No. (\#4: Black female, age 25-34, Associate's degree)

CROSS-CUTTING THEME 2: THE NATURE OF RESEARCH RESULTS-Another common theme that emerged concerned the nature of research results. Interviewees made statements about the nature of individual results in particular - including, for example, statements about expected benefits:

My doctor is only able to do so much research with my blood. I know he sends it to a lab. But if there's a connection between the biorepository and, say, some illness I have, then it could be sent to my doctor. It could possibly save my life. (\#8: Black male, age 45-54, some college but no degree)

as well as potential risks:

Because if they let you know that and they're not absolute, then they cause another problem. (\#34: Black male, age 45-54, some college but no degree)

In general, individual research results were frequently characterized with reference to severity and to treatment. Slightly more than one-third of interviewees mentioned severity (Table 2a), often in the context of the questions "What kind of information would you want to know? Is there any kind of information that you would not want?" Most said they wanted information that had serious health repercussions, using terms such as "detrimental," "terminal," "catastrophic," and "life-threatening." One interviewee specifically thought a researcher's obligations were commensurate with the level of risk implied by the information. A few interviewees did not reference severity, suggesting perhaps that they would like access to any type of information researchers might have about their health.

Although it is not possible to identify a distinct pattern without further study, it is interesting to note that many interviewees seemed to assume that individual research results would concern a currently diagnosable, yet undetected condition:

Give me any kind of information that would help me along. If I had cancer, I sure wouldn't want to go two or three years and they know it and I don't know it. Give it to me. (\#11: Black male, age 55+, Bachelor's degree)

Regardless of what they find out, whatever kind of diseases they find out that I have, I would want to know about it. (\#30: Black female, age 55+, high school graduate)

I think if it's a life-threatening disease I should be notified, because evidently I don't know it. Even if they found out that, God forbid, I might have a tumor or cancer building up and I don't know it and I'm thinking I'm healthy, I think they should get in touch with somebody. Like send me a letter: Oh, by the way, we found some cancer 
on you or ... you know, you might not be living that much longer. (\#32: Black female, age $35-44$, high school graduate)

Nearly one-third of interviewees mentioned treatment (Table 2b), also when talking about information they would want or not want. Many seemed to assume that an intervention would be available, saying they wanted to have the information so that they could take action. Some specifically did not want individual results if treatment were not available, noting, for example, that in such situations "ignorance can be bliss." Others, however, assigned value to the information itself, and wanted any kind of information without regard to treatment.

\section{CROSS-CUTTING THEME 3: EXPECTATIONS CONCERNING ACCESS TO}

RESEARCH RESULTS-Interviewees' expectations concerning access to individual and aggregate research results constituted a third major theme. Almost three-quarters of interviewees said they would not expect to get individual results, based on their understanding of the information conveyed in the form. Several specifically noted that they had no prior expectation of receiving such results:

This is a collective thing, you know. I really understood that from the very beginning. (\#36: Male, "other" race, age 35-44, high school graduate)

I don't think they go in, when people do stuff like that, I don't think they go in there with those types of expectations. I just don't think that. I think it's going to take more than just mine to save the world. (\#20, Black female, age 45-54, some college but no degree)

When asked whether the consent form statement "You should not expect to get individual results from research done with your blood" affected their opinion about participating in the biorepository, only about $10 \%$ of interviewees said yes. However, as described in the original report, most interviewees thought they should have access to at least some individual results. Frequently cited reasons included many of the concepts discussed here, such as the serious nature of the anticipated information and the opportunity to seek treatment, as well as the idea that researchers would have more or newer knowledge than physicians. Another reason given was "courtesy," meaning that delivering serious information about one's health was viewed as the right or decent thing to do:

INTERVIEWER: If researchers discovered something serious about your health, do you think they would let you know about it?

SUBJECT: I would hope so. Just forget the research part of it, just for human decency. Just the fact that ... even though you're not supposed to, it's just the right thing to do. And for protection of other people in the world. It may be something I could transmit or anything to another person. So if it's something that's life-threatening or damaging, of course I think they should notify me. (\#29: Black female, age 35-44, some college but no degree)

INTERVIEWER: If researchers discovered something serious about your health, do you think they would let you know about it?

SUBJECT: I hope they would, out of common courtesy.

INTERVIEWER: Do you think they should know let you know about it?

SUBJECT: Out of common courtesy. (\#19: Black male, age 45-54, some college but no degree)

Two other concepts emerged as important for explaining interviewees' expectations concerning access to research results. Reciprocity, mentioned by about one-fifth of 
interviewees, was among the most commonly cited reasons why access to results—individual and/or aggregate - was expected. The opportunity to stay updated about the outcomes of the research, mentioned by about one-third of interviewees, was the most common reason why access to aggregate results was expected.

Reciprocity (Table 3a) was invoked by interviewees who described access to individual research results as a fair exchange for providing their biological sample and information (as opposed to courtesy, a concept reflecting basic notions of right and wrong). Interviewees who mentioned reciprocity clearly anticipated mutual benefit, i.e., that in exchange for helping researchers, the individual results they would get would be beneficial or helpful to them.

Reciprocity and mutual benefit were also commonly mentioned by interviewees when discussing the importance of receiving aggregate research results, who described such information as an indirect benefit or a type of compensation. As noted, however, the most frequent reason interviewees gave for expecting access to aggregate research results was to stay updated (Table $3 \mathrm{~b}$ ) about the kinds of research being done and discoveries being made through the biorepository. Some interviewees mentioned an interest in information about a particular condition they or a family member might have, while others described a general interest in medical research. Another significant motivation for wanting to stay updated was to know the outcome or contribution of participating in the biorepository:

INTERVIEWER: How important would it be to you to be able to get general news about studies being done through the biorepository?

SUBJECT: I think it would be nice. I mean, if they never contacted you and told you anything, you could wonder, well, what happened to that? Did it help or... It would mean a lot. (\#26: White female, age 55+, high school graduate)

I would like to know what they're focusing on and what they're finding out. Just to see the result, you know, that this research is contributing to something or someone, helping someone or society. (\#31: Female, “other" race, age 45-54, Master’s degree)

CROSS-CUTTING THEME 4: PRACTICAL ISSUES IN PROVIDING ACCESS TO RESEARCH RESULTS-A final cross-cutting theme related to practical considerations involved in providing access to research results. These included logistical issues, such as time, cost, and tracking participants over a long-term project, as well as the question of to whom such results should be provided - the participant or his/her physician.

Logistical issues were mentioned by approximately one-third of interviewees (Table 4a). These types of considerations arose most often in response to the question "What do you think about the statement that 'you should not expect to get individual results from research done with your blood'?" and also in the context of interviewees explaining why they would not expect individual results. A few, however, felt such issues should not be insurmountable, referencing another statement in the consent form that "If you agree, someone from the biorepository will contact you no more than once a year to update [your personal] information":

Because if they're calling you up and wanting to find out how your health is, it seems to me like they could mention something. (\#22: White female, age 45-54, Master's degree)

With regard to interviewees' preferences concerning whom to contact with results (Table $4 \mathrm{~b}$ ), nearly $60 \%$ chose their doctor when asked, "If researchers were going to provide individual results, would you want them to contact you directly with the information, or contact your doctor first?" Commonly mentioned reasons were related to the physician-patient relationship 
(e.g., comfort level, physician's familiarity with their history and background, and ability to communicate with their physician), as well as their physician's ability to interpret the information. Help interpreting information that might be too technical was also mentioned by another interviewee who was among the approximately $10 \%$ who wanted researchers to contact both them and their doctor.

However, among the nearly $30 \%$ of interviewees who wanted to be contacted directly with the information, some thought using their physician as an intermediary might cause delays in receiving the information due to messages being lost or changing doctors. Others simply noted, "it is my health."

\section{Discussion}

Research participants' interest in research results has been amply documented. In our study, over $75 \%$ of interviewees thought researchers should provide access to at least some kinds of individual results. At the same time, almost $75 \%$ said they would not expect to get individual results, based on their understanding of the consent form, and approximately $90 \%$ said this would not affect their opinion about participating in the biorepository.

In addition, we asked a series of open-ended questions that illuminated some of the underlying ideas that shaped interviewees' perspectives on this topic. Many expressed multifaceted views of the nature of research, noting important differences between research and medical care and between the obligations and knowledge of researchers versus physicians when it comes to communicating health-related information. Interviewees' assumptions that the results would have serious and possibly immediate health implications and that treatment would be available featured prominently in their conceptions of the nature of research results, as well as their desire for such results. Their expectations concerning access to research results, both individual and aggregate, were also motivated by notions of courtesy, reciprocity, and staying updated about the outcomes of research. Several recognized logistical challenges associated with providing access to results, including potential trade-offs in terms of both research resources and privacy.

These findings offer an interesting comparison to other recent studies that addressed access to research results in the context of biobanking. Kaufman and colleagues (2008) conducted an online survey of 4,659 U.S. adults about a proposed large genetic cohort study. Survey participants viewed a 3-minute video that described the goals and design of the proposed study and then answered a series of questions concerning the influence of study burden, compensation, and receipt of individual research results on willingness to participate. Nine in ten respondents agreed that they would want to know all of their individual research results, and $91 \%$ wanted their individual research results about health risks "even if there was nothing [they] could do about them." Returning research results was associated with increased willingness to participate. Ormond and colleagues (2009) conducted 200 telephone interviews with participants in the NUgene project, Northwestern University's biobank. During the original consent process, participants had been given the option to agree that "that someone may contact me in the future with research results that may have a significant impact on my health care," but were told this would be a rare occurrence and that it was extremely unlikely that they would be contacted. During the telephone interviews, when asked, "What is your perception of whether or not you will receive any genetic test results from your participation in NUgene?" one-third of participants said they had no expectation for results, one-third mentioned hope for results, and one-third said they expected to be contacted "if there was something severe that I might need to know." Similarities and differences between the findings in these studies and the present study require further study, but may be explained in part by the research method (e.g., closed-ended survey questions versus qualitative interviews), the study population (general population versus biobank participants), and the amount of information 
provided (e.g., a description of a proposed study versus a complete consent form). Taken together, they highlight the importance of exploring the complexities behind participants' opinions and preferences concerning access to research results.

In general, participant input is an important element of sound policy development. Other essential elements include core ethical and legal principles, as well as the ability to conduct beneficial research without undue burden and cost. Thus, the ways that stakeholder perspectives come to be utilized in policy development is a vital issue for continued discussion. As one commentator noted, "Providing that there is proper disclosure ... the choice for the individual is to participate on the terms offered or not. There is a 'negative right' not to be included in the research without consent. There is no 'positive right' for a biobank to be run in such a way just because an individual would like it to be so" (Shickle, 2006). At the same time, developing policies that are responsive to participant perspectives-within the parameters of the purpose of research and the responsible use of research resources-may enhance scientific validity through increased participation rates and promote public support of the research enterprise.

\section{Best Practices}

Vigorous debate concerning participant access to research results will no doubt continue and evolve (Haga \& Beskow, 2008). One likely outcome is that there will be an exceedingly small number of cases in which researchers are obligated to offer individual results and a large number of cases in which it may be ethically permissible to do so (Ossorio, 2006).

For biorepositories in particular, their long-term nature suggests that a prudent approach may be to proceed with caution but consider "never saying never" with regard to offering individual results (Haga \& Beskow, 2008). In our study, many participants perceived differences between research and medical care, and between the obligations of researchers as compared to physicians, and had some appreciation of the logistical issues involved in returning results. Even so, most expected to be informed of findings related to a serious condition-particularly if it was something unlikely to be found in a routine visit with their physician and treatment was available - as a matter of common courtesy and reciprocity. These findings suggest that informed consent processes should be designed to further promote understanding of the research purpose of the biorepository and to avoid conflating the role of researchers with that of physicians (Beskow et al., 2001), but perhaps not prohibit outright the possibility of disclosing at least some kinds of results (National Bioethics Advisory Commission, 1999). Further, our finding that many interviewees seemed to think that individual research results would relate to a currently diagnosable, yet undetected condition awaits further evaluationbut may suggest a justification for focusing on results with clinical meaning when deciding which results should be offered (as opposed to results with personal meaning, as has been suggested [Ravitsky \& Wilfond, 2006]).

Planning for the possible need to disclose individual results is key, and researchers should address this issue in their research protocols (Beskow et al., 2001; National Bioethics Advisory Commission, 1999). Biorepositories should also consider developing a plan to make information about aggregate results readily available to participants, ideally in a form easily understandable by a non-science audience (Haga \& Beskow, 2008). According to participants in our study, access to aggregate results was important as a matter of reciprocity and staying updated about the outcomes of the research.

\section{Research Agenda}

We conducted cognitive interviews to assess prospective participants' understanding and opinions of information conveyed in a biorepository consent form. Strengths of our study 
included (a) the diversity of our study population; (b) the detailed description participants received of the biorepository's purpose, procedures, risks, and benefits by virtue of reading the entire consent form; (c) the emergent quality of the analysis; and (d) the ability to compare coding between independent researchers. Interviewees were asked about hypothetical participation in a biorepository, however, and their perspectives may differ somewhat from those of individuals in an actual consent setting. Although our study sample was diverse, it was geographically limited, and our findings may not be generalizable to all populations.

Our interviews covered a wide array of topics related to biorepository participation and our sample size was adequate to reach saturation on the major concepts mentioned during a 30minute interview. However, we had limited time to probe responses, including those on the series of questions we asked concerning access to research results, and our sample size was too small to carry out analyses stratified by demographic characteristics. Further research, exploring the themes and concepts revealed here, is needed. Such research should focus on gaining more insight into the factors that influence participants' interest in research results, such as their perceptions of the purpose of research and their role in it; their trust in and expectations of researchers and medical professionals; and their understanding and potential misunderstanding of the nature of research results. The latter should include further examination of participants' definition of something "serious" about their health, the idea that the results would relate to a currently diagnosable yet undetected condition, and assumptions that treatment would be available. Related questions include:

- The effect of context: How do the views of patients enrolled in a clinical trial differ from "healthy volunteers" who provide biospecimens for unspecified future use?

- The effect of socio-demographic characteristics: Do opinions concerning access to research results vary significantly by population group?

- The effect of aggregate results: To what extent would the routine provision of aggregate results satisfy participants' desire to know the outcomes of research?

- The effect of logistical challenges: How do participants weigh the economic and privacy costs of providing access to individual results relative to their interest in such results?

\section{Educational Implications}

When designing studies and implementing informed consent processes, investigators and their research teams should be aware of the controversy surrounding access to research results. Not providing such results has been the norm in genetic research (Manolio, 2006), and researchers may not realize the range of opinions and understandings held by prospective participants.

\section{Acknowledgments}

The authors thank Elizabeth Dean, M.A., and Timothy Flanigan, M.A., of RTI International for their assistance conducting the cognitive interviews, and the anonymous reviewers for their insightful comments. This research was supported by a grant from the NIH CTSA (Clinical and Translational Science Award) 1UL1RR 024128-01 to Duke University and by the Duke Institute for Genome Sciences \& Policy.

\section{Biographies}

Laura M. Beskow, M.P.H., Ph.D., is Assistant Professor at the Duke Institute for Genome Sciences \& Policy. Her research focuses on ethics and policy issues in large-scale genomic research and translation, with a particular emphasis on informed consent. Dr. Beskow is the Associate Director of the ethics core at the Duke Translational Medicine Institute and chairs 
the Informed Consent Task Force of the Consent and Community Consultation Workgroup for the Electronic Medical Records and Genomics (eMERGE) Network. With regard to the present project, Dr. Beskow developed the biorepository consent template, designed the original study, and supervised the original data collection. She assisted in coding the data on access to research results, and led the analysis and interpretation of the data. She drafted the manuscript, made critical revisions for important intellectual content, and approved the final version.

Sondra J. Smolek is a doctoral candidate in the Department of Sociology and a trainee at the Center for Genomics and Society at the University of North Carolina at Chapel Hill. She is presently studying the ethical, legal, and social issues related to the development of large-scale genomic studies and genetic research. Her dissertation research is on the experiences of mothers of children with fragile $\mathrm{X}$ syndrome, an inheritable genetic disorder. With regard to the present project, Ms. Smolek led the coding of the data, and assisted in the analysis and interpretation of the results. She provided critical input on important intellectual content of the manuscript and approved the final version.

\section{References}

Beskow LM, Burke W, Merz JF, Barr PA, Terry S, Penchaszadeh VB, Gostin LO, Gwinn M, Khoury MJ. Informed consent for population-based research involving genetics. JAMA: The Journal of the American Medical Association 2001;286(18):2315-2321. [PubMed: 11710898]

Beskow LM, Dean E. Informed consent for biorepositories: Assessing prospective participants' understanding and opinions. Cancer Epidemiology, Biomarkers \& Prevention 2008;17(6):1440-1451.

Bookman EB, Langehorne AA, Eckfeldt JH, Glass KC, Jarvik GP, Klag M, Koski G, Motulsky A, Wilfond B, Manolio TA, Fabsitz RR, Luepker RV. Reporting genetic results in research studies: Summary and recommendations of an NHLBI working group. American Journal of Medical Genetics, Part A 2006;140A(10):1033-1040. [PubMed: 16575896]

Clayton EW, Ross LF. Implications of disclosing individual results of clinical research. JAMA: The Journal of the American Medical Association 2006;295(1):37. [PubMed: 16391213]

Dixon-Woods M, Jackson C, Windridge KC, Kenyon S. Receiving a summary of the results of a trial: Qualitative study of participants' views. British Medical Journal 2006;332(7535):206-210. [PubMed: 16401631]

Fernandez CV. Public expectations for return of results—Time to stop being paternalistic? American Journal of Bioethics 2008;8(11):46-48. [PubMed: 19061110]

Fernandez CV, Kodish E, Weijer C. Informing study participants of research results: An ethical imperative. IRB: Ethics \& Human Research 2003;25(3):12-19. [PubMed: 14569989]

Haga SB, Beskow LM. Ethical, legal, and social implications of biobanks for genetics research. Advances in Genetics 2008;60:505-544. [PubMed: 18358331]

Kaufman D, Murphy J, Scott J, Hudson K. Subjects matter: A survey of public opinions about a large genetic cohort study. Genetics in Medicine 2008;10(11):831-839. [PubMed: 19011407]

Knoppers BM, Joly Y, Simard J, Durocher F. The emergence of an ethical duty to disclose genetic research results: International perspectives. European Journal of Human Genetics 2006;14(11):1170-1178. [PubMed: 16868560]

Manolio TA. Taking our obligations to research participants seriously: Disclosing individual results of genetic research. American Journal of Bioethics 2006;6(6):32-34. [PubMed: 17085403]

Meltzer LA. Undesirable implications of disclosing individual genetic results to research participants. American Journal of Bioethics 2006;6(6):28-30. [PubMed: 17085401]

Miller FA, Christensen R, Giacomini M, Robert JS. Duty to disclose what? Querying the putative obligation to return research results to participants. Journal of Medical Ethics 2008;34(3):210-213. [PubMed: 18316466]

National Bioethics Advisory Commission. Research Involving Human Biological Materials: Ethical Issues and Policy Guidance, Volume 1: Report and Recommendations of the NBAC. Rockville, MD: NBAC; 1999. Available online at http://www.bioethics.gov/reports/past_commissions/nbac_biological1.pdf 
Ormond KE, Cirino AL, Helenowski IB, Chisholm RL, Wolf WA. Assessing the understanding of biobank participants. American Journal of Medical Genetics, Part A 2009;149A(2):188-198. [PubMed: 19161150]

Ossorio PN. Letting the gene out of the bottle: A comment on returning individual research results to participants. American Journal of Bioethics 2006;6(6):24-25. [PubMed: 17085399]

Parker LS. Rethinking respect for persons enrolled in research. American Society for Bioethics \& Humanities Exchange 2006;9:6-7.

Partridge AH, Burstein HJ, Gelman RS, Marcom PK, Winer EP. Do patients participating in clinical trials want to know study results? JNCI: Journal of the National Cancer Institute 2003;95:491-492.

Partridge AH, Wolff AC, Marcom PK, Kaufman PA, Zhang L, Gelman R, Moore C, Lake D, Fleming GF, Rugo HS, Atkins J, Sampson E, Collyar D, Winer EP. The impact of sharing results of a randomized breast cancer clinical trial with study participants. Breast Cancer Research \& Treatment 2009;115(1):123-129. [PubMed: 18543100]

Ravitsky V. Disclosing individual genetic results to research participants. American Journal of Bioethics 2006;6(6):8-17. [PubMed: 17085395]

Richards MPM, Ponder M, Pharoah P, Everest S, Mackay J. Issues of consent and feedback in a genetic epidemiological study of women with breast cancer. Journal of Medical Ethics 2003;29(2):93-96. [PubMed: 12672889]

Schulz CJ, Riddle MP, Valdimirsdottir HB, Abramson DH, Sklar CA. Impact on survivors of retinoblastoma when informed of study results on risk of second cancers. Medical \& Pediatric Oncology 2003;41:36-43. [PubMed: 12764741]

Shalowitz DI, Miller FG. Disclosing individual results of clinical research: Implications of respect for participants. JAMA: The Journal of the American Medical Association 2005;294(6):737-740. [PubMed: 16091577]

Sharp RR, Foster MW. Clinical utility and full disclosure of genetic results to research participants. American Journal of Bioethics 2006;6(6):42-44. [PubMed: 17085408]

Shickle D. The consent problem within DNA bio-banks. Studies in History and Philosophy of Biological and Biomedical Sciences 2006;37(3):503-519. [PubMed: 16980191]

U.S. Department of Health and Human Services. Code of Federal Regulations, Protection of Human Subjects: 45 CFR 46. 2005. Available online at http://www.hhs.gov/ohrp/humansubjects/guidance/45cfr46.htm

Wendler D, Emanuel E. The debate over research on stored biological samples: what do sources think? Archives of Internal Medicine 2002;162(13):1457-1462. [PubMed: 12090881] 


\section{WILL I FIND OUT THE RESULTS OF THE RESEARCH? You} should not expect to get individual results from research done with your blood. Researchers must study samples from many people over many years before they can know if the results have meaning. The results will not affect your care right now. They will not be given to your doctor and will not be put in your medical record. You can get general news about studies being done through the biorepository at [URL].

FIG. 1.

Biorepository Consent Form Text Concerning Access to Research Results. 
1. All Interviews: What do you think about the statement that "you should not expect to get individual results from research done with your blood"?

2. All Interviews: Does this [the fact that you should not expect individual results] affect your opinion about participating?

3. For Interviews \#1-10 only: When you think about biorepository researchers and your own doctor, how would you compare their responsibilities when it comes to communicating something important about your health?

4. For Interviews \#11+: If researchers discovered something serious about your health, do you think they would let you know about it?

5. For Interviews \#11+: Do you think they should let you know about it?

6. For Interviews \#11+: What kind of information would you want to know? Is there any kind of information that you would not want to know (e.g., information about a serious health concern when there is no treatment)?

7. For Interviews \#11+: Would you want researchers to contact you directly with the information, or contact your doctor first?

8. All Interviews: How important would it be to you to be able to get general news about studies being done through the biorepository?

FIG. 2.

Interview Questions Concerning Access to Research Results. 


\section{TABLE 1}

TABLE 1A. Research Relative to Medical Care

Research and medical care are different:

- "If they find out something, they won't let you know, because that's supposed to be a research thing. It's not like a medical treatment that they have to tell you there's something in there. It's a random blood test ... not diagnosis or treatment or anything." (\#3: Asian female, age 45-54, some college but no degree)

- 'I'm sure they're going to have millions and millions of samples, so they're not going to individually contact each person. It really is not that type of testing anyway.... You really can't expect a follow-up. It's not like a regular doctor visit.” (\#35: Black male, age 3544 , associate's degree)

Biological sample versus person:

- $\quad$ Different: "I mean, it's in a repository, so it's not just your personal medical treatment. Your sample could sit on a shelf with a million others, a little drop here, a little drop there, and so they're not geared specifically toward you. They're just overall samples." (\#5: Black male, age 35-44, Bachelor's degree)

- Not different: "I'm giving you part of my body-I mean my blood—that's pretty personal." (\#17: Asian male, age 25-34, some college but no degree)

- Ownership:

INTERVIEWER: What do you think about the statement that "you should not expect to get individual results from research done with your blood"?

SUBJECT: The very same thing: once I give it, it's theirs. It doesn't bother me. (\#37: Native American female, age 55+, some college but no degree)

TABLE 1B. Obligations of Physicians versus Researchers

Obligations are different:

- $\quad$ "I mean, with my doctor, I expect my doctor to tell me if there's something wrong. Them, I don't really ... that's not really their responsibility. Their responsibility is to research whatever they're researching." (\#1: White female, age 18-24, GED)

- $\quad$ "My own personal doctor, his obligation is to treat me and my condition, so he has a personal obligation to do the best he can for me personally. As opposed to the researchers, where they're not really geared toward the patient as much as toward the sample.....There's not an actual person attached to it any more. So it would be a different level of obligation with a random sample as opposed to an actual patient who needs care." (\#5: Black male, age 35-44, Bachelor's degree)

Obligations are different, but still want some research results:

- $\quad$ "I think it's practical that I shouldn't expect it. However, I would hope that if there was something wrong with me and, as a result of this, there was an easy fix, that somehow that information should be able to get back to my doctors." (\#10: White male, age 55+, Bachelor's degree)

- $\quad$ "I think it would be nice. I can't say that I think they should, but it would be very nice if they did. I mean, some people want to know and some don't. Some people want to know what's wrong with them and some don't. I think it's better to know than not know. You have to decide if you want to seek help. I know that's not what their commitment is for this situation, but I'd say it would be very, very, very important if something really major-not minor-I think that they should find my name against my code and call me up." (\#20: Black female, age 45-54, some college but no degree)

Obligations are not different:

- "I think it's the Hippocratic Oath they would all have to take." (\#2: Native American female, age 45-54, some college but no degree)

- $\quad$ SUBJECT: As medical professionals, they have the responsibility to communicate to me anything which affects me.

INTERVIEWER: Both the biorepository researchers and your doctor?

SUBJECT: Yes. (\#2: Asian male, age 45-54, bachelor's degree)

TABLE 1C. Physician versus Researcher Knowledge

Physician would already know about any health problems:

J Empir Res Hum Res Ethics. Author manuscript; available in PMC 2010 June 24. 
TABLE 1C. Physician versus Researcher Knowledge

- "What I'm saying is that prior to [researchers] getting that, I would hope that my doctor would have figured all of that out." (\#25: Black female, age 45-54, Master's degree)

- "Again, what this research includes and how that potentially could uncover something that wasn't necessarily picked up on in my routine examinations by my personal physician, that's a little bit of a stretch for me.” (\#27: Black male, age 45-54, Master's degree)

- "Well, if I thought there was a problem or whatever, I would expect to get results from the physician, not who's been taking my survey. So if I were, you know, if something was wrong, I should know this before I do a survey or supply my blood to know whether or not it's okay for me to go ahead and let someone do it. I should already have been tested, or whatever." (\#29: Black female, age 35-44, some college but no degree)

- $\quad$ "I would think if it's something life threatening, [my doctor] would have found it out himself." (\#37: Native American female, age 55 + , some college but no degree)

Researchers would have more/newer knowledge:

- "Yeah, I think personally, of course, they should tell you about it because maybe they have newer tests, maybe they have different tests than the average doctor to determine whatever disease you have that the average doctor might not." (\#17: Asian male, age 2534 , some college but no degree)

- $\quad$ "No, I would want to know. Because if you have this knowledge and my doctor is running millions and millions of tests on me and they can't find nothing and you have the knowledge and you have the cure in knowing what's wrong for me, please tell me." (\#32: Black female, age 35-44, high school graduate)

- $\quad$ "If it's serious and something that wouldn't ordinarily be detected by symptoms or a physical or a regular check-up, then yes, they should." (\#33: Asian male, age 25-34, Bachelor's degree) 


\section{TABLE 2}

TABLE 2A. Severity

Want information with serious health repercussions:

- $\quad$ "I would want to know information that would put my health or life in jeopardy. If it was determined through research that I could be at risk for something terminal or catastrophic, some kind of disease or something. I would want to know that. And I realize there are those who would not want to know that.” (\#12: Black female, age 45-54, Master's degree)

- INTERVIEWER: What kind of information would you want to know, if any?

SUBJECT: Well, if they found out I had cancer or something, something life-threatening.

INTERVIEWER: Is there any kind of information you would not want?

SUBJECT: I can't think of anything I would not want. Like if it were Alzheimer's or something, I know some people might not want to know, but I think I'd want to know. If they thought I was susceptible to it or was starting to get it or something, I think I would want to know. (\#22: White female, age 45-54, Master's degree)

- "I wouldn’t expect them to go out of their way to contact me unless it was something serious and detrimental health-wise." (\#7: White male, age 55+, GED)

Researchers' obligation to provide information is commensurate with severity:

- SUBJECT: I guess I feel that the lower the risk, the less I would feel like I need to know, the less I would feel they would have a moral obligation. And that would go up equally with the....

INTERVIEWER: With the risk level?

SUBJECT: Yeah. (\#18: White female, age 25-34, bachelor's degree)

Want any information (without regard to severity):

- INTERVIEWER: What kinds of information would you want to know?

SUBJECT: Anything that concerned me or my health.

INTERVIEWER: Is there any kind of information that you would not want?

SUBJECT: No. (\#26: White female, age 55+, high school graduate)

TABLE 2B. Treatment

Assume treatment will be available:

- "I would want to know the condition, how it would affect me, and what should I do to get treated for that." (\#14: White male, age 55 + , professional degree)

- INTERVIEWER: So if the researchers do find something serious about your health, you would want to know?

SUBJECT: You're dern right. You know, "guess what, we did come up with something to cure you." (\#15: Black male, age 45-54, high school graduate)

- INTERVIEWER: What kind of information would you want to know?

SUBJECT: If I did have cancer or diabetes or heart trouble or something like that. If I had some rare virus or something that needed treatment. (\#21: Black female, age 35-44, Bachelor's degree)

- $\quad$ "Some people want to know what's wrong with them and some don't. I think it's better to know than not know. You have to decide if you want to seek help." (\#20: Black female, age 45-54, some college but no degree)

Do not want information if treatment is not available:

- INTERVIEWER: Is there any kind of information that you would want to know or would not want to know?

SUBJECT: Not at this time. I'm not exactly sure. I'm undecided on that one.

INTERVIEWER: If researchers were doing something with your blood, and say they found a gene for a disease that could be fatal or make you very ill, then you would not expect them to tell you about it? 
TABLE 2B. Treatment

SUBJECT: No, I wouldn't expect them to tell me about it.

INTERVIEWER: Would you want them to?

SUBJECT: I wouldn't want them to either. Unless they're going to treat me, I wouldn't want them to tell me. (\#16: Black male, age 35-44, Master's degree)

- If it was life-threatening and there was no treatment, I would say probably just don't even let me know. Why make me panic for the rest of my life when there's nothing I can do about it, you know. Ignorance can be bliss. If there was a life-threatening thing that was treatable, I would certainly want to know about it.” (\#18: White female, age 25-34, Bachelor's degree)

- "If there is no treatment, I don’t want to know because I would always worry.” (\#31: Female, “other” race, age 45-54, Master’s degree)

Information is always good (without regard to treatment):

- INTERVIEWER: What kind of information would you want to know? Is there any kind of information that you would not want?

SUBJECT: That I would not want to know? No, I think information is always good. So as much information as you could give me would be great. There is nothing I'd not want to know. (\#17: Asian male, age 25-34, some college but no degree) 


\section{TABLE 3}

TABLE 3A. Reciprocity

Fair exchange:

- "So if I'm helping you out doing this big study, I think that the least you could do is make one phone call—just once a year, make one phone call. Call me and give me a heads-up. I don't think that would be too much to ask." (\#17: Asian male, age 25-34, some college but no degree)

- INTERVIEWER: If researchers discovered something serious about your health, do you think they would let you know about it?

SUBJECT: I would hope so. I really would, since I was nice enough to donate it. I really would. (\#20: Black female, age 45-54, some college but no degree)

Mutual benefit:

- "I mean, you'd also think that if you were giving your blood [and] there would be something that would help you in some type of way, you'd be notified of it." (\#15: Black male, age 45-54, high school graduate)

- $\quad$ "I would hope so, I would want to know. Not only would I be helping by giving them the blood, if they found something, I hope they would help me by telling me what it was that they found.” (\#39: Black female, age 35-44, high school graduate)

Aggregate results:

- "It would be a nice benefit to have some access to some of the research information since you did willingly volunteer. You don't get any direct benefits, so at least you'll have some type of access to see what's going on." (\#5: Black male, age 35-44, Bachelor's degree)

- "It would be real important. If I'm going to provide my time, my blood, why not?" (\#8: Black male, age 45-54, some college but no degree)

- $\quad$ "For me, that would be like a compensation. Not a payment but like a compensation. This is just ... you're an insider, you know. You helped people and so maybe you get this information about this also.” (\#36: Male, "other" race, age 35-44, high school graduate)

\section{TABLE 3B. Staying Updated}

Particular interest:

- INTERVIEWER: What kinds of things are you thinking about [with regard to general news about studies being done through the biorepository]?

SUBJECT: What's new out in the diabetes scene. What's new out in blood pressure things. Because I have both of those, and I try to kind of keep up with what's going on and really what's new. (\#11: Black male, age 55+, Bachelor's degree)

General interest:

- INTERVIEWER: You mentioned about getting general news about the biorepository. How important is that to you?

SUBJECT: I would say I think it's important. I personally would probably just follow up on it because I have an interest in that kind of thing. (\#18: White female, age 25-34, Bachelor's degree) 


\section{TABLE 4}

TABLE 4A. Logistical Issues

- " I can only imagine if they had to give information to everybody that participated, that would be a lot of money and a lot of time." (\#1: White female, age 18-24, GED)

- "You'll never know how many people are involved with that particular research. It just takes too much time trying to back-track and locate people that have been involved with the studies. People move. People pass away. It's just too much.” (\#4: Black female, age 25-34, Associate's degree)

- "Well, I would love to find out, but I understand that it would add tremendously to the cost of the research to notify everybody. Plus, we're supposed to be confidential, so how can we be confidential if we're receiving reports regularly. It would be kind of a lot. I just think ... I wouldn't want the research to be that expensive. Then the drugs are going to be that much more expensive. It's a nice idea, but practically it probably wouldn't work out to have reports, to find out." (\#22: White female, age 45-54, master's degree)

- "Well, it would be nice to hear from it, but I guess they don't have the time to inform everybody. " (\#26: White female, age 55+, high school graduate)

\section{TABLE 4B. Whom to Contact With Results}

Physician-Physician-patient relationship:

- $\quad$ "Probably I'd like them to contact my physician first because the physician would know ... it's somebody you're more familiar with. They're going to have the time to sit there and chat with you about it rather than a researcher who's got a deadline due in an hour or something." (\#18: White female, age 25-34, Bachelor's degree)

- $\quad$ "First doctor, then patient because then the doctor would probably know how to go about assessing the problem related to the patient. I'm not the expert; the physician, they would need to know first." (\#29: Black female, age 35-44, some college but no degree)

- "I think [my doctor] should be. He knows my health. It might be something I'd hear and go screaming." (\#37: Native American female, age $55+$, some college but no degree)

- $\quad$ "I know that sounds crazy, for them to not contact me but contact the doctor, but I would probably feel better with him getting the information to me because I'm more comfortable with him.” (\#34: Black male, age 45-54, some college but no degree)

Physician-Information too technical:

- INTERVIEWER: And if they did contact you, would you want them to contact you or your doctor first?

SUBJECT: Both.

INTERVIEWER: Okay, so maybe have a discussion with you and the doctor at the same time?

SUBJECT: Yes. There might be some terms when I would go, "What?"

INTERVIEWER: And then the doctor can explain it?

SUBJECT: Exactly. (\#38: Male, undisclosed race, age 25-34, some college but no degree)

Participant:

- $\quad$ "It would be okay to contact me directly. Messages to doctors, I mean, I know that would be important and it would probably come through. But doctors' offices can get a little hectic, and I think I'd rather get it straight from them than count on messages not getting lost in doctors' offices." (\#22: White female, age 45-54, Master's degree)

- "Me directly, because I might have changed doctors. Because it is my health. Doctors hardly have time now." (\#31: Female, "other" race, age 45-54, Master's degree) 